\title{
Participação da comunidade na gestão e controle social da política de saúde.
}

\section{Community participation in management and social control of health policy.}

\section{La participación comunitaria en la gestión y el control social de las políticas de salud.}

\author{
Fátima Ferretti ${ }^{1}$ \\ Lucimare Ferraz ${ }^{2}$ \\ Maria Elisabeth Kleba ${ }^{3}$ \\ Bernardo Boccalon ${ }^{4}$ \\ Deborah Cristina Amorim ${ }^{5}$ \\ Dunia Comerlatt ${ }^{6}$
}

RESUMO: O controle social é a forma pela qual os cidadãos garantem participação nas decisões que interferem nas políticas públicas. Para identificar o conhecimento da comunidade acerca dos órgãos representativos para o controle social em saúde, assim como os indivíduos que os representam nos Conselhos Locais de Saúde (CLS) foi tomado como campo de investigação o território de um Núcleo de Apóio à Saúde da Família do Município de Chapecó - SC. Os domicílios que serviram como amostra foram selecionados aleatoriamente por meio das fichas A dos cadastros dos agentes comunitários de saúde, nos quais era realizado um questionário estruturado com perguntas sobre uso e acesso aos serviços de saúde. Os resultados evidenciaram que a prática do controle social não é utilizada por uma grande parcela da população, sendo esse uma possível forma para busca de melhoria do serviço e do vínculo serviço-comunidade. Por isso, ainda que os Conselhos de Saúde sejam espaços em que a população tenha a participação como garantia uma efetividade maior só 1 Professora e Coordenadora Adjunta do Mestrado em Ciências da Saúde da Universidade Comunitária da Região de Chapecó (Unochapecó). Endereço para correspondência: Av. Senador Attílio Fontana,591- Chapecó- Bairro Efapi CEP: 89809-000, Caixa postal: 1141E-mail: ferrettifisio@yahoo.com.br.

2 Doutora em Saúde Coletiva, docente do Mestrado em Ciências da Saúde, na Universidade Comunitária da Região de Chapecó (Unochapecó), Chapecó-SC, Brasil.. E-mail: 1ferraz@unochapeco.edu.br.

3 Pós-graduada em Políticas Sociais e Dinâmicas Regionais; Pós-Graduada em Ciências da Saúde. Universidade Comunitária da Região de Chapecó (Unochapecó), Chapecó-SC, Brasil. E-mail: 1kleba@unochapeco.edu.br. 4 Graduando do curso de graduação em Medicina, na Universidade Comunitária da Região de Chapecó (Unochapecó), Chapecó-SC, Brasil. E-mail: bernardo_boccalon@unochapeco.edu.br.

5 Assistente Social, Mestre em Serviço Social pela UFSC e docente na área de Ciências Humanas e Jurídicas na Universidade Comunitária da Região de Chapecó-SC, Brasil. E-mail: deborah@unochapeco.edu.br.

6 Assistente Social, Doutora na área de Serviço Social pela Pontifícia Universidade Católica do Rio Grande do Sul. E-mail:dunia@unochapeco.edu.br. 
será alcançada quando houver maior envolvimento dos usuários neste processo.

Palavras-Chave: Conselhos de Saúde. Participação Comunitária. Sistema Único de Saúde. Saúde Pública.

ABSTRACT: Social control is the way in which citizens ensure participation in decisions that affect public policy. To identify the knowledge of the community about the representative institutions for social control in health, as well as individuals representing them in the Local Health Councils (CLS) was taken as a research field the territory of one support the Center for Family Health of the Chapecó-SC. Households that served as sample were randomly selected through the sheet A of the records of community health workers, in which it was carried out a structured questionnaire with questions about use of and access to health services. The results showed that the practice of social control is not used by a large portion of the population, this being a possible way to search for improvement of service and service-community bond. Therefore, although the health councils are spaces where the population has participation as guarantee greater effectiveness will only be achieved when there is greater involvement of users with this process.

Keywords: Health Councils. Consumer Participation. Unified Health System. Public Health.

RESUMEN: El control social es la forma en que los ciudadanos garantizan la participación en las decisiones que afectan a la política pública. Para identificar el conocimiento de la comunidad sobre los órganos de representación para el control social en salud, así como las personas que los representan en los Consejos Locales de Salud (CLS) fue tomada como un campo de investigación en el territorio de un soporte del Centro de Salud Familiar de la Chapecó-SC. Los hogares que sirvieron de muestra fueron seleccionados al azar a través de los registros de los registros de los trabajadores de la salud de la comunidad, en la que se llevó a cabo un cuestionario estructurado con preguntas sobre el uso y el acceso a los servicios de salud. Los resultados mostraron que la práctica de control social no es utilizado por una gran parte de la población, siendo esta una posible manera de buscar para la mejora del servicio y el servicio en la comunidad de bonos. Por lo tanto, a pesar de los consejos de salud son espacios donde la población tiene participación como garantía de una mayor eficacia sólo se logra cuando hay una mayor participación de los usuarios en este proceso. Palabras clave: Consejos de Salud. Participación Comunitaria. Sistema Único de Salud. Salud Pública.

\section{INTRODUÇÃO}

O controle social é uma das formas pelas quais os cidadãos garantem participação nas decisões que influenciam as políticas públicas. Com a redemocratização do país na década de 1980, esse sentimento participativo sofreu grande influência do movimento denominado Reforma Sanitária, o qual buscava transformações na área da saúde brasileira ${ }^{1}$.

A participação social, ou seja, o envolvimento dos cidadãos nas decisões políticas foi, e tem 
sido amplamente discutida em vários fóruns. Cabe destacar que a partir da $8^{\circ}$ Conferência Nacional da Saúde (CNS), realizada em 1986, foi criado o Sistema Unificado e Descentralizado de Saúde (SUDS). Apesar de ainda não prever a centralidade do município na gestão do sistema, esse já possuía como princípios básicos a universalização, descentralização, regionalização, equidade, participação comunitária e hierarquização². Já em 1988, com a promulgação da Constituição da República Federativa do Brasil, em seus Art. 196 a 200, há uma retomada, segundo Cotta, Cazal e Martins ${ }^{3}$, das propostas originais da Reforma Sanitária, mediante a criação do Sistema Único de Saúde (SUS) e com a Constituição são instituídas as diretrizes básicas do SUS a descentralização, a atenção integral e a participação da comunidade.

A regulamentação do SUS se deu após dois anos de sua criação, por meio das Leis Orgânicas da Saúde (LOS) 8080/90 e 8142/90. A primeira, além de dispor sobre as condições para a promoção, proteção e recuperação da saúde, trata da sua organização, princípios e diretrizes ${ }^{4}$. A segunda, dispõe sobre a participação da comunidade e institui os Conselhos de Saúde em todas as esferas governamentais definidos como órgãos colegiados, permanentes, com caráter deliberativo ${ }^{5}$.

Os Conselhos de Saúde devem contar com a participação da comunidade, atuando na formulação, proposição e execução das Políticas Públicas ${ }^{6}$, mas também no controle social, exercido por meio da fiscalização, do acompanhamento e avaliação das políticas de saúde. Para Cotta et al. ${ }^{7}$, o controle social "deve ser concebido como resultado da participação direta da população no processo de gestão pública, resultando na apropriação pela sociedade de meios e instrumentos para planejar, fiscalizar e analisar as ações e os serviços de saúde". Sua composição como órgão colegiado, se dá por meio de representantes do governo, profissionais de saúde, usuários e prestadores de serviço, garantindo-se a seguinte proporcionalidade dos membros: 50\% usuários, $25 \%$ representantes dos trabalhadores e os outros $25 \%$ das vagas restantes preenchidas por representantes do governo e prestadores de serviço ${ }^{8}$.

Cabe ressaltar que os Conselhos de Saúde possuem regimento próprio, seja para definir o número de conselheiros, o número de reuniões ordinárias e extraordinárias, assim como o tempo de mandato. Esse regimento deve respeitar o disposto em leis federais, como a proporcionalidade dos representantes e seu caráter deliberativo.

Para Kleba et al. ${ }^{9}$, as funções desses órgãos podem ser agrupadas em cinco categorias que caracterizam seu potencial de intervenção sobre ações, programas e políticas de saúde: deliberar, fiscalizar, normatizar ou registrar, assessorar ou prestar consultoria e informar ou comunicar. Isso os caracteriza como conselhos gestores, mecanismos institucionalizados de controle social, que assumem papel fundamental como parceiros corresponsáveis na gestão da saúde.

Entretanto, para o Ministério da Saúde, o fortalecimento da mobilização e do controle social em saúde deve ser promovido por meio de outros canais de comunicação entre governo e cidadãos, com vistas a viabilizar a participação da sociedade na construção de novos modelos de atenção e gestão 
em saúde, "regidos sob a lógica das necessidades, demandas e direitos de toda a população"10. Tais iniciativas, como a promoção da educação popular, capacitação de lideranças, entidades de classe e movimentos populares, devem se pautar no princípio da equidade e favorecer a inclusão de especificidades dos diferentes grupos sociais.

Em muitos municípios brasileiros, além dos conselhos gestores da política de saúde foram criados Conselhos Locais de Saúde, com vistas a promover a participação da comunidade na construção da saúde junto ao território de sua adstrição à unidade de saúde. O Conselho Local de Saúde difere dos Conselhos de Saúde institucionalizados e constituídos nas três esferas legislativas, por ser um órgão consultivo e não deliberativo, que tem como objetivo aproximar a comunidade da unidade de saúde local ${ }^{1}$. Além de garantir acesso às informações sobre o funcionamento dos serviços, bem como sobre atividades da administração municipal, os Conselhos Locais de Saúde intensificam o vínculo entre unidade de saúde e comunidade na busca de resolução para os problemas identificados pela própria população, na mobilização e no fortalecimento de potencialidades ${ }^{11}$.

De forma geral, os conselhos se constituem espaços de exercício da cidadania, quando incluem a voz e os interesses dos usuários, mas também em espaços de aprendizagem, seja sobre conteúdos como saúde, funcionamento dos serviços e da gestão pública ${ }^{2}$, seja de habilidades como argumentar e assumir corresponsabilidades. Cotta, Cazal e Martins ${ }^{3}$ salientam o caráter da participação como um processo que se constrói participando; "não é um conteúdo que se possa transmitir, tampouco uma destreza que se possa adquirir pelo mero treinamento, mas outrossim, uma mentalidade e um comportamento a ser construído pela reflexão crítica e pelo amadurecimento do cidadão."

Práticas democráticas efetivas, que possam fortalecer a participação e o controle social requerem uma nova cultura política democrática, que institua processos efetivos de comunicação entre os gestores da política, conselheiros e a sociedade de forma geral. Nesse sentido, vários autores ressaltam dificuldades relativas ao exercício da participação social, na forma preconizada pela legislação e pelas políticas norteadoras da organização do SUS.

Dentre as dificuldades, está a permanência de resquícios do paternalismo, clientelismo e autoritarismo, fazendo com que os indivíduos continuem a aceitar que outras pessoas decidam por si. Oliveira, Ianni e Dallari ${ }^{12}$ afirmam que a restrita participação social está associada a fatores socioculturais, tais como "a falta de tradição participativa e de cultura cívica no país, a tradição autoritária do estado brasileiro e a cultura política dominante". A falta de vontade política e a dificuldade de o gestor partilhar poder decisório no espaço do conselho são salientadas por diferentes autores ${ }^{3,7,12}$.

Outro entrave que esclarece, em parte, a reduzida participação dos usuários nos conselhos é a dificuldade de compreensão da linguagem técnica utilizada por profissionais e gestores em reuniões, o baixo reconhecimento da própria comunidade em relação às funções dos membros do conselho de saúde e ao caráter voluntário desse cargo $^{10,3}$. Esse aspecto de voluntariado pode 
desestimular a participação, visto que, numa sociedade capitalista, a valoração da função está associada aos benefícios financeiros que esta garante, quanto mais importante o cargo, maior a remuneração. Bispo Júnior e Martins ${ }^{13}$ destaca que em nossa vivência prevalece um imediatismo e individualismo, no qual as pessoas demonstram, muitas vezes, apenas interesses por ações que os tragam benefícios pessoais diretos e imediatos.

Já, aqueles que se dispõem a participar enfrentam outros obstáculos, como a falta de capacitação para atuar na função de conselheiro e a intimidação que os representantes dos serviços de saúde podem exercer. Para além das questões que podem se constituir como entraves da participação dos usuários, Grisotti, Patrício e Silva ${ }^{14}$, chamam atenção que, em muitas realidades, o conselho gestor funciona apenas como um órgão legitimador das ações governamentais e não deliberativo, desestimulando a participação social.

Como tentativa de transformar esse cenário, a Política Nacional da Atenção Básica definiu, como um de seus princípios a participação social e enfatizou que essa deve ser estimulada, "possibilitando o enfrentamento dos determinantes e condicionantes de saúde, na organização e orientação dos serviços de saúde a partir de lógicas mais centradas no usuário e no exercício do controle social" ${ }^{15}$. Mas, para que a comunidade desenvolva seu legítimo poder de controle social, necessita da apropriação de conhecimentos. Oliveira, Ianni e Dallari ${ }^{12}$ afirmam que "a participação só será possível quando a sociedade, em sua diversidade, tiver o aporte de conhecimentos que promovam não só a sua efetiva participação, mas, principalmente, o gosto em participar”.

Considerando o contexto apresentado e reconhecendo que a participação dos usuários é fundamental no controle social, o objetivo do presente estudo foi identificar o conhecimento da comunidade acerca dos órgãos constituídos para o exercício da participação da comunidade e controle social em saúde, tomando como campo de investigação o território de um Núcleo de Apoio à Saúde da Família.

\section{METODOLOGIA}

O estudo caracteriza-se como exploratório-descritivo, com abordagem mista - quantitativa e qualitativa -, desenvolvido no território de um dos Núcleos de Apoio à Saúde da Família (NASF) de um município Polo em Saúde da Região Oeste do Estado de Santa Catarina. Esse território foi definido, em diálogo entre o gestor municipal de saúde e pesquisadores.

Os instrumentos de coleta de dados foram construídos com a participação de profissionais ligados à gestão da saúde, em especial a gerência da Atenção Básica, buscando contemplar questões que pudessem contribuir com a qualificação do planejamento e controle social da política de saúde nas equipes da Estratégia Saúde da Família (ESF). Os instrumentos aplicados nessa pesquisa foram testados num estudo piloto, e amplamente debatidos no grupo de pesquisadores e profissionais da saúde. A análise dos dados ficou sob a responsabilidade dos docentes dos programas sob a supervisão das coordenadoras da pesquisa. 
Na perspectiva quantitativa, utilizou-se como delineamento um estudo transversal, definindo-se como população as famílias cadastradas pelos centros de saúde inseridos no referido NASF, num total de 13.866, de acordo com os dados do SIAB de fevereiro de 2011. A amostra selecionada foi de 1.133 famílias, com erro amostral de $3 \%$ e proporção de perda em $10 \%$.

A seleção dos domicílios (famílias participantes) foi aleatória, por meio das fichas A dos cadastros dos agentes comunitários de saúde (ACS) pertencentes aos centros de saúde já referidos. Num primeiro momento, foram reunidos os prontuários das famílias de acordo com sua microárea de residência, sendo então todos os prontuários agrupados em uma única pilha; em seguida foi selecionada a oitava família (número sorteado pela equipe de pesquisadores) e, a partir dessa, as próximas subsequentes com intervalo de 12 prontuários, até atingir o valor da amostra determinado para cada centro de saúde. Na terceira etapa, houve a confirmação com o ACS responsável pela família, se a mesma ainda residia no endereço registrado e se havia restrição de horário para a visita/ entrevista, procedendo-se, neste caso, sorteio de nova família. Todas as 1.133 famílias selecionadas foram visitadas, porém, 110 foram excluídas, uma vez que não aceitaram fazer parte do estudo ou por não terem sido encontradas em seus domicílios por três tentativas consecutivas de busca. Desta forma, a amostra total foi composta por 1.023 famílias.

A coleta de dados foi realizada por meio de um questionário estruturado, aplicado por acadêmicos, previamente capacitados, nas residências das famílias sorteadas. Para participar da pesquisa, o respondente precisava ter 18 anos ou mais.

Para o tratamento dos dados foram utilizadas técnicas próprias para um estudo quantitativodescritivo, as quais informam sobre número e percentual da distribuição de um determinado evento na população em estudo, neste estudo apresentados por frequência simples nas tabelas 1 e 2 . Os dados coletados foram digitados no programa Excel; na sequência sofreram o processo de controle de qualidade com análise de coerência e consistência. Após a correção de erros de digitação procedeu-se a análise estatística dos dados, com o auxilio do programa Statistical Package for Social Science (SPSS).

Na perspectiva qualitativa, foi utilizada como técnica de coleta de dados a Estimativa Rápida Participativa (ERP), que tem por finalidade orientar o processo de diagnóstico situacional comunitário. Segundo Kleba et $\mathrm{al}^{16}$, a técnica da ERP viabiliza identificar, em curto período de tempo, problemas e necessidades consideradas relevantes por sujeitos sociais interessados em sua resolução, bem como potencialidades que requerem recursos e investimentos para sua manutenção ou fortalecimento.

De acordo com a proposta da estimativa rápida, foram realizadas entrevistas seguindo um roteiro de perguntas com 20 lideranças, duas por área de referência à equipe da ESF, sendo estas selecionadas por meio da indicação da equipe, tendo como critério representarem diferentes organizações e serem referências na comunidade. O número de lideranças foi definido considerando a viabilidade de acesso e tempo disponível para a coleta de dados. Da mesma forma, o roteiro de perguntas foi construído em diálogo com gestores e profissionais dos serviços, questionando as lideranças 


\section{$57 / /$}

quanto ao modo de organização da comunidade, a participação da população, ao conhecimento dos gestores sobre participação e controle social, a situações difíceis ocorridas no último ano e a forma como a comunidade se organizou para buscar uma solução. As entrevistas foram realizadas na residência, ou outro local, definido pelas lideranças, garantindo privacidade e confidencialidade aos entrevistados.

A análise dos dados qualitativos foi através da leitura sistemática das entrevistas transcritas, a partir desta leitura buscou-se identificar no depoimento dos entrevistados unidades de registro que pudessem expressar ideias relevantes em relação as questões norteadoras da pesquisa. O processo analítico seguiu os preceitos propostos por Minayo $^{17}$ para uma análise temática do conteúdo de pesquisa, a partir do qual foi possível identificar três categorias, sendo: Os Conselhos de Saúde e a comunidade; A participação e a ação da comunidade; O papel do Conselho no controle social do orçamento.

Com relação aos aspectos éticos da pesquisa, o projeto foi aprovado pelo Comitê de Ética em Pesquisa da Universidade Comunitária da Região de Chapecó sob Parecer 001/2011, com base na Resolução do Conselho Nacional de Saúde do Ministério da Saúde.

\section{RESULTADOS E DISCUSSÃO}

O município de Chapecó, em sua rede de saúde, dispõe de 26 Centros de Saúde, com um total de 41 equipes da ESF, o que corresponde a mais de 75\% de cobertura da população. Em 2010, o município instituiu quatro Núcleos de Apoio à Saúde da Família (NASF), sendo que o selecionado para este estudo integra oito equipes da ESF.

\section{Os conselhos de saúde e a comunidade}

Com o objetivo de identificar o conhecimento dos usuários acerca dos Conselhos de Saúde, os entrevistados tinham que responder as questões encontradas nas Tabelas 1 e 2. A primeira e a segunda perguntas questionavam se o entrevistado já ouviu falar ou conhecia o Conselho Municipal de Saúde e o Conselho Local de Saúde, respectivamente; a terceira pergunta questionava se conhecia algum conselheiro. Todas as perguntas obtiveram uma frequência maior da resposta "não", evidenciando o desconhecimento da comunidade sobre esses fóruns e seus representantes.

Tabela 1 - Conhecimento de usuários sobre Conselho Municipal e Local de Saúde, de um município pólo em saúde da região Oeste do Estado de Santa Catarina, 2012.

\begin{tabular}{ccccc}
\hline \multicolumn{1}{c}{ Pergunta/Resposta } & Sim & Não & Ignorado/Não respondeu & Total \\
\hline $\begin{array}{c}\text { Já ouviu falar/conhece o } \\
\text { Conselho Municipal de } \\
\text { Saúde? }\end{array}$ & $45 \%(\mathrm{n} .459)$ & $53,9 \%(\mathrm{n} .552)$ & $1,1 \%(\mathrm{n} .12)$ & 1023 \\
$\begin{array}{c}\text { Já ouviu falar/conhece o } \\
\text { Conselho Local de Saúde de } \\
\text { seu bairro? }\end{array}$ & $32,5 \%(\mathrm{n} .332)$ & $66,8 \%(\mathrm{n} .683)$ & $0,7 \%(\mathrm{n} .8)$ & 1023 \\
$\begin{array}{c}\text { Você conhece algum } \\
\text { conselheiro? }\end{array}$ & $12,8 \%(\mathrm{n} .131)$ & $86,4 \%(\mathrm{n} .883)$ & $0,8 \%(\mathrm{n} .9)$ & 1023 \\
& & & & \\
\hline
\end{tabular}


Já, referente à participação dos usuários no Conselho Local de Saúde, a tabela 2 demonstra que $88,6 \%$ dos entrevistados nunca participaram do Conselho.

Tabela 2 - Participação dos usuários no Conselho Local de Saúde, de um município polo em saúde da região Oeste do Estado de Santa Catarina, 2012.

\begin{tabular}{cccc}
\hline Pergunta/Resposta & Sim & Não & Total \\
\hline $\begin{array}{c}\text { Já participou do Conselho } \\
\text { Local de Saúde? }\end{array}$ & $11,5 \%$ (n.106) & $88,5 \%$ (n.811) & 917 \\
Entre os que participaram & Como conselheiro & Como ouvinte & \\
Total & $43,4 \%(\mathrm{n} .46)$ & $56,6 \%(\mathrm{n} .60)$ & 106 \\
& 152 & 871 & 1023 \\
\hline
\end{tabular}

Constata-se que há pouca participação da comunidade nos conselhos locais de saúde. Esse fato desestrutura/desestabiliza a proposição de que os Conselhos Locais de Saúde se constituam como espaços democráticos de controle social e propositivos de ações em prol da comunidade. Segundo Busana, Heidemann e Wendhausen ${ }^{18}$ :

É através da participação popular nos conselhos de saúde, aliada à vontade de realizar transformações políticas e sociais, que este processo se constituirá em ferramenta essencial para o desenvolvimento do empoderamento individual e coletivo, uma vez que tal processo modifica o status quo ao promover uma consciência política e suscitar autonomia para a tomada de decisão.

Além de ouvirmos os usuários dos serviços de saúde, entrevistamos as lideranças (identificadas pelos profissionais de saúde) da comunidade, que confirmam, de certa forma, o pouco envolvimento da comunidade nos conselhos, uma vez que $60 \%$ das lideranças desconhecem algum conselheiro do bairro, $40 \%$ nunca participaram das reuniões dos conselhos, $25 \%$ referem desconhecer os Conselhos de Saúde e apenas 20\% já foi ou é conselheiro no Conselho Local de Saúde. Dentre àquelas que já participaram de alguma reunião, a maioria refere ter sido convidada por intermédio das agentes comunitárias de saúde, o que, segundo elas, deve-se ao fato de fazerem parte da associação de bairro ou do conselho da comunidade. Para essas, o Conselho Local realiza um bom trabalho, apesar de que pode melhorar.

A visibilidade dos conselhos junto à comunidade é salientada por Cotta, Cazal e Martins ${ }^{3}$ como fundamental para o efetivo exercício do controle social. Para esses autores, os conselhos são desconhecidos por grande parte dos cidadãos, o que demonstra distanciamento não apenas entre representantes e seus representados, mas dos conselhos com a população de forma geral. Democratizar as informações indica compromisso dos conselheiros, garantindo maior confiabilidade nos mecanismos participativos e promovendo corresponsabilidade entre os diferentes segmentos sociais. Além disso, "cumpre um papel educativo junto à população, porque mostra a possibilidade da real efetivação da participação da sociedade civil na gestão compartilhada de políticas públicas". 
Para Oliveira, Ianni e Dallari ${ }^{12}$, a participação social pode ser fortalecida à medida que houver uma cultura política que promova o reconhecimento do outro como cidadão, o que também é favorecido por meio da prática associativa que promove vínculos sociais, legitimando a representação nos conselhos. Nesse sentido, o Conselho Nacional de Saúde reforça a importância do diálogo, da articulação e do intercâmbio dos Conselhos e entidades, movimentos populares, instituições públicas e privadas para a promoção da Saúde ${ }^{15}$.

Além da participação da comunidade nos Conselhos Locais de Saúde, buscamos saber, junto às lideranças, quais os grupos importantes existentes na comunidade, e esses enfatizaram os grupos de idosos e o de mulheres, porque promovem atividades físicas, de lazer e culturais, bem como oportunizam o debate sobre assuntos de interesse para a comunidade. Apenas em uma comunidade houve destaque ao grupo de jovens. Contudo, na opinião da maioria das lideranças, os jovens têm resistência e não têm aderido aos convites para participar de reuniões no bairro. Entre as entidades institucionalizadas, foram citadas com maior frequência as iniciativas das igrejas, como sua atuação, juntamente com a associação dos moradores. Dentre as atividades, destacam a construção de uma praça e um ginásio para a comunidade, bem como a atuação da pastoral da comunidade no apoio a um grupo de autoajuda envolvendo usuários de drogas. Outras iniciativas citadas favoráveis à promoção da saúde na comunidade foram: atividades culturais, formativas, recreativas e educativas desenvolvidas com grupos de diferentes faixas etárias por um Centro Comunitário e por Centros de Tradições Gaúchas (CTG).

As iniciativas de mobilizações comunitárias relatadas pelas lideranças vêm ao encontro da Política Nacional de Atenção Básica, pois essa política tem como fundamento e diretriz o estimulo à participação e o controle social, como forma de ampliar a autonomia e capacidade do cuidado à sua saúde a partir de lógicas mais centradas no usuário e no exercício do controle social. Devendo ser características do processo de trabalho das equipes de Atenção Básica à implementação de diretrizes de qualificação dos modelos de atenção e gestão tais como a participação coletiva nos processos de gestão, a valorização, fomento a autonomia e protagonismo dos diferentes sujeitos implicados na produção de saúde ${ }^{8}$.

Batagello, Benevides e Portillo ${ }^{19}$ afirmam que esses espaços comunitários surgem como uma possibilidade para superar a significativa dificuldade na efetiva participação da população, construindo novos significados para os ambientes formais de participação social. Lima, Sá e Pinheiro ${ }^{20}$ destacam como novos significados a "construção da identidade pessoal e social de seus moradores, as interações constitutivas dos mesmos, o sentimento de pertença, a vinculação, a ação e o compromisso social", para que através do desenvolvimento das pessoas, o mesmo ocorra com as políticas públicas em suas estratégias e significados.

Entretanto, Coelho ${ }^{21}$ assegura que as políticas referentes à participação social no SUS, somente explicitam a respeito da realização e fortalecimento de conferências e dos conselhos de saúde. Por isso, os demais espaços comunitários, ainda que abordados, são de forma muito vaga, não 
garantindo assim a "força dessas falas nos efetivos processos de construção do SUS".

Assim, para que os Conselhos de Saúde possam assumir e se comprometer com suas competências regimentais na lógica da efetiva participação e no exercício do controle social, Batagello, Benevides e Portillo ${ }^{19}$, garantem que é necessário compreender "que os conselhos de saúde não substituem os movimentos sociais e que são esses movimentos que devem nortear as ações dos conselhos". Por isso, a ampliação das alianças entre instituições públicas, não governamentais e os movimentos sociais devem ser estimulados para qualificar os processos de gestão das políticas públicas.

\section{A participação e a ação da comunidade}

Na busca de compreender a percepção das lideranças sobre a capacidade de ação da comunidade, foi solicitado que citassem alguma situação difícil ocorrida no último ano e de que forma a comunidade se organizou para buscar uma solução. Foram citadas diferentes iniciativas de apoio à melhoria das condições de trabalho nas unidades de saúde, como reformas e ampliação da estrutura física, ampliação do número de funcionários, ou mesmo permanência dos mesmos na unidade para diminuir a rotatividade. Outras iniciativas importantes referem-se a melhorias no bairro reivindicadas junto à prefeitura, como placas com nome das ruas e lombadas, ampliação e ajustes no transporte coletivo e a resolução de problemas relativos ao esgoto. Algumas lideranças citaram o movimento contra o uso de drogas e iniciativas em prol de um trabalho social para famílias mais necessitadas.

De acordo com as lideranças, a organização da comunidade se dá por meio de "reuniões e debates", ou ainda "de assembleias", para as quais "um chama o outro". Dependendo do assunto, "busca-se conhecimento com várias pessoas", cujas informações e esclarecimentos prestados favoreçam a definição de soluções. A rádio comunitária foi citada como canal de mobilização relevante, mas também a motivação "boca a boca" envolvendo relações de vizinhança. Outra forma de mobilizar a comunidade é a promoção de eventos ou a venda de rifas para angariar fundos em ações solidárias. O diálogo com o prefeito ou setores responsáveis foi citado também como iniciativa das lideranças em prol da resolução dos problemas da comunidade.

Vale ressaltar a importância das rádios comunitárias como um dispositivo importante na mobilização da população, pois "o uso da rádio comunitária como espaço dedicado às questões de saúde pode servir como instrumento de advocacia de direitos humanos e sociais, bem como ferramenta de gestão a partir da perspectiva da interatividade com a população"22.

Quando questionados sobre a participação da população nas atividades realizadas na comunidade, a opinião das lideranças diverge: para uns a comunidade participa pouco, porque segundo eles, “as pessoas são acomodadas" e "comparecem para reclamar" nas reuniões. Além disso, "as pessoas precisam ser motivadas a participar; são sempre as mesmas, se quiser reunir as pessoas tem que convidar de casa em casa". Para outros, "o pessoal é bastante comprometido”. Especialmente "nos esportes" a participação é boa; e nas reuniões de "organização da comunidade”, a cada ano 
aumenta a participação.

Como pontos favoráveis ao incremento de ações da comunidade, as lideranças citaram a união, o interesse comum no desenvolvimento da comunidade, mas também a motivação da população por atividades lúdicas e prazerosas. As condições de acesso, como localização do serviço e infraestrutura do bairro, também facilitam a participação.

Entretanto, no que diz respeito às dificuldades à adesão das pessoas em participar na busca de resoluções para os problemas da comunidade, foram citados o " horário das reuniões que coincide com horário de trabalho dos moradores da comunidade", especialmente relativo às reuniões do Conselho Local de Saúde, e "o tempo de intervalo entre as reuniões que acaba desmotivando". Também foi destacado pelas lideranças, que "os grupos mais vulneráveis (com maiores dificuldades financeiras) são os que menos participam", seja por vergonha ou por medo de falar. Outrossim, uma das lideranças refere que "as pessoas estão cansadas de lutar".

As dificuldades em torno da participação das pessoas em prol do bem comum, assim como, da efetivação das políticas públicas, relacionam-se diretamente com o limite de se apoderar de conhecimentos. Para Shimizu et al. ${ }^{23}$ a maior dificuldade que os conselheiros possuem para desenvolverem todas as suas funções é a carência de capacitações.

Além disso, justificativas como a falta de tempo, refletem o sistema econômico vigente, o capitalismo "o qual promove valores individuais e restringe a sociedade ao consumo e à acumulação, além da frustração pelo não reconhecimento da importância da ação social política" configurando assim importantes obstáculos para a mobilização social ${ }^{21}$.

Outros fatores que influenciam negativamente na cultura participativa, segundo Cotta et al. ${ }^{7}$, é a ausência de vontade política para que a cidadania de fato seja exercida. Isso poderá ser modificado quando houver "acumulação de experiências bem sucedidas de união e cooperação entre os cidadãos e o Estado, que reforcem condutas de confiança recíproca, visando à construção de um bem verdadeiramente comum".

Acerca da indicação de que os grupos mais vulneráveis são os que menos participam Oliveira e Pinheiro ${ }^{24}$, apontam uma forte relação entre a apatia política e desigualdades socioeconômicas, em que há pouca participação das classes populares submetidas a condições degradantes, não usufruindo assim de seus direitos fundamentais. Ainda, quando participam, "não se arriscam a pedir a palavra e às vezes não são vistos nem ouvidos quando se atrevem a tal feito.”.

Souza et al. ${ }^{2}$ destacam ser importante a realização de debates sobre participação comunitária no controle social, deste modo, contribuindo "para a reflexão dos Conselheiros quanto à importância de tomarem decisões condizentes com o bem estar e a saúde da população". Assim, torna-se "possível desencadear um processo de participação popular e controle social em saúde, ainda que incipiente, em um microterritório de atuação, garantindo um Sistema Único de Saúde mais ético e 
equânime"25.

\section{O papel do Conselho de Saúde no controle social do orçamento}

Os Conselhos de Saúde, instituídos como mecanismos de controle social, com caráter deliberativo, fiscalizador, normatizador e informativo têm o dever legal de formular estratégias e controlar a execução das políticas públicas de saúde, inclusive no aspecto financeiro. Sendo assim, Cunha e Magajewski ${ }^{26}$ afirmam que o acompanhamento e execução dos planos de saúde, em relação aos gastos e os resultados previstos deve ter a participação ativa desse órgão.

Para que os conselhos possam atuar no planejamento e controle dos atos governamentais, é essencial que a administração pública preste contas de seus atos. A Resolução no . 333/2003 do Conselho Nacional de Saúde dispõe sobre o conteúdo dessa prestação, a qual inclui andamento da agenda de saúde pactuada; relatório de gestão; montante, fonte e forma de aplicação dos recursos; auditorias iniciadas e concluídas no período; oferta e produção de serviços na rede assistencial ${ }^{8}$.

Gonçalves, Gonçalves e Tavares ${ }^{27}$ afirmam que "é por meio da prestação de contas que os dirigentes demonstram o que fizeram e seu planejamento para transformar a realidade de seus representados". Somente por meio deste mecanismo é que a sociedade poderá exercer sua função de fiscalizar os investimentos públicos, bem como propor ações para melhorar a adequação do orçamento as necessidades de saúde da comunidade.

Entretanto, o relatório da $11^{\text {a }}$ Conferência Nacional de Saúde aponta, que os mecanismos de prestação de contas que os conselhos recebem, não têm permitido o controle sobre as fontes de financiamento, o esclarecimento sobre a aplicação dos recursos públicos e o acompanhamento de resultados da execução dos planos de saúde ${ }^{28}$.

Têm sido utilizados instrumentos complexos na prestação de contas, dificultando a compreensão, a avaliação e, consequentemente, o controle social. Um exemplo disso, segundo Fleury et al. ${ }^{29}$, é o balancete periódico, mecanismo mais utilizado para a prestação de contas das secretarias de saúde, o qual possui uma linguagem essencialmente técnica, e por isso representa um obstáculo ao avanço da transparência se não for combinada com outras formas de prestação de contas, pois há dificuldade no entendimento das informações ofertadas.

Assim, parece não haver interesse por parte dos órgãos de controladoria interna e dos próprios governos em facilitar o controle externo, exercido pelos conselhos. Ainda, é preciso reconhecer que a Constituição Federal e as políticas dela decorrentes são desconhecidas de parcela significativa da população brasileira, o que contribui para a pouca participação da população nos processos de controle social, conforme evidenciado na tabela 2.

Além disso, autores referem outros obstáculos enfrentados pelos conselhos, tais como a periodicidade incerta das reuniões, o pouco tempo para análise detalhada dos gastos, discussão 
insuficiente entre os conselheiros, ausência de conhecimento prévio do orçamento aprovado, informação repassadas de modo sintético e a dependência financeira do órgão, que pode ser usada como moeda de troca em aprovações de pareceres $^{23,14,27,30}$.

Para empoderar os conselheiros quanto as suas atribuições de fiscalizar, deliberar sobre o orçamento municipal de saúde e utilizar em benefício do bem estar e desenvolvimento comunitário, são necessárias capacitações contínuas ${ }^{27}$.

No entanto, Kleba et al. ${ }^{9}$ afirma que "a efetivação destas atribuições somente ocorrerá quando, os conselheiros compreenderem as implicações que suas decisões podem exercer sobre a conformação do modelo e das práticas assistenciais", visto que não há regras que responsabilizem os conselhos e seus representantes pelos resultados e impactos de suas deliberações ${ }^{31}$.

Para Leite, Lima e Vasconcelos ${ }^{32}$ uma vez que se compreende e assume as competências regimentais que é atribuído ao Conselho de Saúde, este ampliaria seu papel, superando essa atribuição de aprovador de projetos rotineiros, ou apenas para aquisição de financiamentos, tornando-se mais efetivo na participação e no controle social, propiciando transparência, eficácia e equidade na utilização dos recursos públicos.

\section{CONSIDERAÇÕES FINAIS}

O presente estudo explicita que a participação da comunidade e o controle social ainda são desconhecidos por parcela significativa da população. É possível inferir que a recente tradição democrática no país; o baixo conhecimento acerca dos Direitos Humanos; a compreensão equivocada de cidadania (muito centrada na capacidade de ter e consumir); a forma ainda conservadora de conduzir a gestão pública, centralizada no poder e decisão por parte de governos, interferem para o distanciamento da população na gestão da política pública de saúde.

A legislação brasileira, desde as leis orgânicas das diferentes políticas públicas, incorporou valores, conceitos e diretrizes que buscam fortalecer a descentralização do Estado, a participação social e a integralidade de atendimento na saúde. Essa área de política pública é complexa tanto no que se refere às ações desenvolvidas nas diferentes modalidades, a fim de atender as demandas de indivíduos e grupos, quanto no que se refere aos processos de gestão pública.

Os conselhos de políticas públicas, instâncias de controle social do Estado por parte sociedade, devem estimular a participação social, fortalecendo a relação entre governo e sociedade na gestão das ações de caráter público. Há que se criar estratégias para capacitar os conselheiros, democratizar as informações, promover a troca de experiências e discussão dos limites e possibilidades da representação. Para isto é preciso ativar o processo de educação permanente junto aos Conselheiros de Saúde, possibilitando reflexões sobre temas relevantes que contribuirão para o melhor entendimento do seu papel e suas atribuições, especialmente no que se refere a gestão do controle social do SUS. 


\section{REFERÊNCIAS BIBLIOGRÁFICAS}

1. Matuoka RI, Ogata MN. Análise qualitativa dos conselhos locais de atenção básica de São Carlos: a dinâmica de funcionamento e participação. [Internet]. Rev. de APS, América do Norte. 2010 Nov;13(4). [ Acesso em: 10 out. 2013]. Disponível em: http://www.aps.ufjf.br/index.php/ aps/article/view/572/385.

2. Souza TO, Silva JM, Nobrega SS, Constancio JF. Controle social: um desafio para o conselheiro de saúde. [Internet]. Rev. bras. enferm., Brasília. 2012 abr;65(2):215-221. [Acesso em: 12 out. 2013]. Disponível em: http://www.scielo.br/pdf/reben/v65n2/v65n2a03.pdf.

3. Cotta RMM, Cazal MM, Martins PC. Conselho Municipal de Saúde: (re) pensando a lacuna entre o formato institucional e o espaço de participação social. [Internet]. Ciênc. saúde coletiva, Rio de Janeiro. 2010 ago;15(5):2437-2445.[ Acesso em: 13 out. 2013]. Disponível em: http:// www.scielo.br/pdf/csc/v15n5/v15n5a18.pdf.

4. Brasil. Lei $\mathrm{n}^{\circ}$ 8080, de 19 de setembro de 1990. Dispõe sobre as condições para a promoção, proteção e recuperação da saúde, a organização e o funcionamento dos serviços correspondentes e dá outras providências. [Internet]. [Acesso em: 11 nov. 2013]. Disponível em: http://www. planalto.gov.br/ccivil_03/leis/18080.htm.

5. Brasil. Lei n 8.142, de 28 de dezembro de 1990. Dispõe sobre a participação da comunidade na gestão do Sistema Único de Saúde (SUS) e sobre as transferências intergovernamentais de recursos financeiros na área da saúde e dá outras providências. [Internet]. [Acesso em: 11 nov. 2013]. Disponível em: http://www.planalto.gov.br/ccivil_03/leis/18142.htm.

6. Brasil. Ministério da Saúde. Conselho Nacional de Saúde. Resolução no 333, de 4 de novembro de 2003. Aprova as diretrizes para criação, reformulação, estruturação e funcionamento dos conselhos de saúde; 2003.

7. Cotta RMM, Martins PC, Batista RS, Franceschinni SCC, Priore SE, Mendes FF. O controle social em cena: refletindo sobre a participação popular no contexto dos Conselhos de Saúde. [Internet]. Physis: Rev. de saúde coletiva, Rio de Janeiro. 2011 jul;21(3):1121-1137. [Acesso em: 10 out. 2013]. Disponível em: http://www.scielo.br/pdf/physis/v21n3/19.pdf.

8. Brasil. Ministério da Saúde. Coletânea de normas para o controle social no Sistema Único de Saúde / Ministério da Saúde. Conselho Nacional de Saúde. Brasília: Ministério da Saúde; 2011. 208 p. (Série E. Legislação de saúde).

9. Kleba ME, Matielo A, Comerlatto D, Renk E, Colliselli L. O papel dos conselhos gestores de políticas públicas: um debate a partir das práticas em Conselhos Municipais de Chapecó (SC). [Internet]. Ciênc. saúde coletiva, Rio de Janeiro. 2010 mai;15(3):793-802. [Acesso em: 11 out. 
2013]. Disponível em: http://www.scielo.br/pdf/csc/v15n3/v15n3a22.pdf.

10. Brasil. Ministério da Saúde. Secretaria de Gestão Estratégica e Participativa. Política Nacional de Gestão Estratégica e Participativa no SUS - ParticipaSUS . 2. ed. p.19. Brasília: Editora do Ministério da Saúde; 2009.

11. Ponte HMS, Filho JOL, Feijão JRP, Souza FL, Santos EV, Soares CHA. "O caminho se faz ao caminhar": processo de reativação de conselhos locais de saúde em Sobral, a partir do protagonismo cidadão. [Internet]. Saúde soc., São Paulo. 2012 mai;21(supl. 1):234-243. [Acesso em: 09 out. 2013]. Disponível em: http://www.scielo.br/pdf/sausoc/v21s1/20.pdf.

12. Oliveira AMC, Ianni AMZ, Dallari SG. Controle social, no SUS: discurso, ação e reação. [Internet]. Ciênc. Saúde Coletiva, Rio de Janeiro. 2013 ago;18(8):2329-2338. [Acesso em: 10 out. 2013]. Disponível em: http://www.scielo.br/pdf/csc/v18n8/17.pdf.

13. Bispo Junior JP, Martins PC. Envolvimento comunitário na Estratégia de Saúde da Família: dilemas entre institucionalização e efetiva participação. [Internet]. Physis: Rev. de saúde coletiva, Rio de Janeiro. 2012; 22(4):1313-1332. [Acesso em: 12 out. 2013]. Disponível em: http://www.scielo.br/pdf/physis/v22n4/a04v22n4.pdf.

14. Grisotti M, Patricio ZM, Silva A. A participação de usuários, trabalhadores e conselheiros de saúde: um estudo qualitativo. [Internet]. Ciênc. saúde coletiva, Rio de Janeiro. 2010 mai;15(3):831-840. [Acesso em: 11 out. 2013]. Disponível em: http://www.scielo.br/pdf/csc/ v15n3/v15n3a26.pdf.

15. Brasil. Ministério da Saúde. Secretário de Atenção à Saúde. Departamento de Atenção básica. Política de Atenção Básica. [Internet]. Brasília. 2012. [Acesso em: 12 out. 2013]. Disponível em: http://189.28.128.100/dab/docs/publicacoes/geral/pnab.pdf.

16. Kleba ME, Duarte TF, Romanini A, Cigognini DC, Althaus IR. Estimativa Rápida Participativa como ferramenta de diagnóstico na Estratégia Saúde da Família. Grifos, Chapecó, 2015, 24(38/39):159-177. [Acesso em: 23 de set. de 2016]. Disponível em: http://bell. unochapeco.edu.br/revistas/index.php/grifos/article/view/3279/1888

17. Minayo MCS. O desafio do conhecimento: pesquisa qualitativa em saúde. $12^{\mathrm{a}}$ ed. São Paulo: Hucitec; 2010.

18. Busana JA; Heidemann ITSB, Wendhausen ÁLP. Participação popular em um conselho local de saúde: limites e potencialidades. Texto contexto - enferm. Florianópolis, 2015, 24(2):442-449.

19. Batagello R, Benevides L, Portillo JAC. Conselhos de saúde: controle social e 
moralidade. Saúde soc. São Paulo. 2011;20(3):625-634.

20. Lima DMA, Sa TS, Pinheiro AAA. Fóruns comunitários: uma estratégia de construção participativa do desenvolvimento local. Rev. psicol. Polít. 2012;12:59-70.

21. Coelho JS. Construindo a participação social no SUS: um constante repensar em busca de equidade e transformação. Saúde soc. 2012;21(supl.1):138-151.

22. Gallo PR, Blake MT, Motta-Gallo SKA. Rádio comunitária como mecanismo para participação social no contexto da gestão descentralizada dos serviços de saúde. Rev. bras. crescimento desenvolv. hum. 2011;21(3):841-848.

23. Shimizu HE, Pereira MF, Cardoso AJC, Bermudez XPCD. Representações sociais dos conselheiros municipais acerca do controle social em saúde no SUS. [Internet]. Ciênc. saúde coletiva, Rio de Janeiro. 2013 ago;18(8):2275-2284. [Acesso em: 08 jan. 2014]. Disponível em: http://www.scielosp.org/pdf/csc/v18n8/11.pdf.

24. Oliveira LC, Pinheiro R. A participação nos conselhos de saúde e sua interface com a cultura política. [Internet]. Ciênc. saúde coletiva, Rio de Janeiro. 2010 ago;15(5):2455-2464. [Acesso em: 13 out. 2013]. Disponível em: http://www.scielo.br/pdf/csc/v15n5/v15n5a20.pdf.

25. Soratto J, Witt RR, Faria EM. Participação popular e controle social em saúde: desafios da Estratégia Saúde da Família. Physis. 2010;20(4):1227-1243 .

26. Cunha PF, Magajewski F. Gestão participativa e valorização dos trabalhadores: avanços no âmbito do SUS. Saúde soc. 2012;21(supl.1):71-79.

27. Gonçalves AO, Gonçalves RS, Tavares AL. O olhar dos conselheiros de saúde sobre os relatórios de prestação de contas no município de Natal (Rio Grande do Norte), Brasil. Saúde soc. São Paulo. 2011;20(3):659-672.

28. Brasil. Ministério da Saúde. Conselho Nacional de Saúde. Relatório da $11^{\text {a }}$ Conferência Nacional de Saúde. 2002. [Acesso em: 05 jan. 2014]. Disponível em: http://conselho.saude.gov. br/biblioteca/Relatorios/relatorio_11.pdf.

29. Fleury S, Ouverney ALM, Kronemberger TS, Zani FB. Governança local, no sistema descentralizado de saúde no Brasil. [Internet]. Rev. Panam. Salud. Publica, Washington. 2010 dez;28(6):446-455. [Acesso em: 13 de dez. de 2013]. Disponível em: http://www.scielosp.org/ $\mathrm{pdf} / \mathrm{rpsp} / \mathrm{v} 28 \mathrm{n} 6 / \mathrm{v} 28 \mathrm{n} 6 \mathrm{a} 06 . \mathrm{pdf}$.

30. Benelli SJ, Costa-Rosa A. Conselhos municipais: prática e impasses no cenário contemporâneo. [Internet]. Psicol. estud. Maringá. 2012 dez;17(4):577-586. [Acesso em: 11 de jan. 2014]. Disponível em: http://www.scielo.br/pdf/pe/v17n4/a04v17n4.pdf. 
$67 / /$

31. Bispo Junior JP, Gerschman S. Potencial participativo e função deliberativa: um debate sobre a ampliação da democracia por meio dos conselhos de saúde. [Internet]. Ciênc. saúde coletiva, Rio de Janeiro. 2013 jan;18(1):7-16. [Acesso em: 08 jan. 2014]. Disponível em: http://www.scielo.br/pdf/csc/v18n1/02.pdf.

32. Leite VR, Lima KC, Vasconcelos CM. Financiamento, gasto público e gestão dos recursos em saúde: o cenário de um estado brasileiro. Ciênc. saúde coletiva. 2012;17(7):1849-1856.

Artigo apresentado em 18/12/15

Artigo aprovado em 26/09/16

Artigo publicado no sistema em 10/10/16 